\title{
A Preliminary Comparative Study of Visual Performance Between Two Newly Commercially Available Monofocal Intraocular Lenses Implanted During Cataract Surgery
}

This article was published in the following Dove Press journal:

Clinical Ophthalmology

\author{
Vincenzo Scorcia (D) \\ Mauro Soda' \\ Andrea Lucisano (D) \\ Michele Lanza $\mathbb{( D}^{2}$ \\ Giuseppe Giannaccare (D) \\ 'Department of Ophthalmology, \\ University Magna Græcia, Catanzaro, \\ Italy; ${ }^{2}$ Multidisciplinary Department of \\ Medical, Surgical and Dental Specialities, \\ Università della Campania "Luigi \\ Vanvitelli”, Naples, Italy
}

Purpose: To compare visual outcomes of two newly developed monofocal intraocular lenses (IOLs) (I-Stream H and CT Lucia 211P) implanted in patients undergoing surgery for senile cataract.

Methods: This prospective, comparative, single-center, randomized study included 94 eyes of 94 patients undergoing cataract surgery. Patients were randomized to receive the implantation of I-Stream H IOL (Group 1) or CT Lucia 211P IOL (Group 2). Each patient underwent a complete ocular examination before (V0), 1 month (V1), 3 months (V2) and 6 months (V3) after surgery, including visual acuity testing, objective refraction, slit-lamp biomicroscopy, contrast sensitivity testing and visual function index questionnaire (VF-14). Results: After surgery, a significant increase of best-corrected visual acuity (BCVA), CS and VF-14 and a significant decrease of SE were detected in both groups at each time point compared to baseline (always $\mathrm{p}<0.01$ ). No significant differences in the postoperative increase of BCVA $(p=0.12), C S(p=0.21)$ and VF-14 $(p=0.31)$ and decrease of SE $(p=0.08)$ were detected comparing patients from Group 1 and Group 2 at V3. Mean and median prediction error, as well as absolute prediction error values, did not significantly differ between the two groups ( $p>0.05$ ). Eyes with an actual refraction within $0.25,0.50$ and $1 \mathrm{D}$ were $53.1 \%, 85.1 \%$ and $100 \%$ for Group 1 and $55.3 \%, 87.2 \%$ and $100 \%$ for Group $2(\mathrm{p}>0.05)$.

Conclusion: I-Stream H and CT Lucia 211P allowed a satisfied recovery of visual function after senile cataract surgery; both IOLs were shown to have similar outcomes of visual performance.

Keywords: intraocular lens, IOL, I-Stream H, CT Lucia 211P, cataract surgery

\section{Introduction}

Senile cataract is a progressive opacification of the crystalline lens occurring in the elderly and determining a significant decrease of vision. ${ }^{1}$ Nowadays, surgery is able to restore vision and improve quality of life. Significant advances have been developed in the last years in this field with the development of new phacoemulsification devices and intraocular lenses (IOLs) aiming at improving outcomes while reducing intra- and post-operative complications. ${ }^{2}$

With modern cataract surgery, the aim of IOL implantation is not only to reach the post-operative planus target but also to decrease spherical aberration and ultraviolet retinal toxicity and to improve contrast sensitivity (CS). Factors involved
Correspondence: Vincenzo Scorcia Department of Ophthalmology,

University Magna Græcia, Viale Europa,

Germaneto, Catanzaro 88100, Italy

Tel +393334800929

Fax +3909613647094

Email vscorcia@libero.it 
in the IOL selection are mainly related to patient's characteristics, such as age, expectations, lifestyle, work and hobbies. $^{3}$

In the European market, monofocal IOLs still represent the most used ones in the current surgical practice, mostly due to their lower cost compared to premium IOLs. Another reason is related to a lower rate of visual disturbances since neuroadaptation is rapid, and patients are almost immediately comfortable with their postoperative vision. ${ }^{4}$

I-Stream H (MD Tech, Casoria, Italy) and CT Lucia 211P (Carl Zeiss Meditech, Jena Germany) are two newlycommercially monofocal IOLs. The former IOL is hybrid since it consists of both acrylic hydrophilic (Benz IOL 25, Benz Research \& Development, Sarasota, FL, USA) and hydrophobic co-polymers. The new polymer of 2Hydroxyethylmethacrylate and 2-Ethoxyethylmethacrylate was specifically developed for IOL in order to obtain a combination of elasticity and tensile strength that allows the lens to return to its original shape and optical properties in an extremely short time. The lens geometry is aspheric biconvex with a $360^{\circ}$ square edge.

The latter IOL is made with ultra-high-purity hydrophobic acrylic material with a heparin-coated surface and the $\mathrm{C}$-loop shape allows easy centering in the capsular bag. The optic design is monofocal spheric.

Since to date, no clinical data are available about the visual performance of both IOLs, the purpose of this study was to compare the visual outcomes of I-Stream H and CT Lucia 211P in the setting of senile cataract surgery.

\section{Methods}

Consecutive patients with senile cataract undergoing surgery at the Ophthalmology Unit of University Magna Græcia of Catanzaro (Italy) from January 2018 to January 2019 were enrolled in this comparative, randomized prospective study. The study was performed in accordance with the ethical standards stated in the 1964 Declaration of Helsinki and was approved by the local Ethics Committee (Comitato Etico Regione Calabria Sezione Area Centro). Informed consent was obtained from all subjects before the enrollment in the study.

Inclusion criteria were: good pupil dilatation (at least $6.5 \mathrm{~mm}$ ), nuclear or cortico-nuclear cataract classified as grade 3 according to the Lens Opacities Classification System III scale and a range of IOL from 5 to 30 diopters (D). ${ }^{5}$ Exclusion criteria were: any ocular disease other than senile cataract potentially limiting post-operative full visual acuity, keratometric astigmatism $>1.25 \mathrm{D}$ and use of any type of ocular medications. Each patient underwent a complete ocular examination before (V0) and 1 month (V1), 3 months (V2) and 6 months (V3) after surgery, including the following procedure: visual acuity testing (LogMAR); objective refraction (Nidek AR-310, Tokyo, Japan) for the calculation of: actual refraction (spherical equivalent, SE), mean and median prediction error (calculated as the difference between the predicted postoperative refraction and the actual postoperative refraction), absolute prediction error (mean of the absolute values of prediction errors), and proportion of eyes with a actual refraction within $0.25,0.5$ and $1.0 \mathrm{D}$ compared to predicted one; slitlamp biomicroscopy; CS testing; the administration of visual function index questionnaire (VF-14).

Briefly, CS was measured using a Pelli-Robson Contrast Sensitivity Chart $[\mathrm{M}, \mathrm{N}]$ (Precision Vision, Woodstock, IL, USA) in photopic conditions $\left(85 \mathrm{~cd} / \mathrm{m}^{2}\right)$. This chart is designed to measure CS at low spatial frequencies and is known to be very reliable. Testing distance was $1 \mathrm{~m}$ with the patient's best optical correction for this distance. ${ }^{6,7}$ The subject's score was the logarithmic CS corresponding to the last triplet in which at least 2 out of 3 letters were correctly identified. The VF-14 is a questionnaire specifically designed to measure functional impairment due to cataract consisting of 18 questions covering 14 aspects of visual function. The questionnaire shows high internal consistency and is a reliable, valid instrument providing information not conveyed by visual acuity or general health status measures. ${ }^{8,9}$

IOL power and predicted postoperative refraction were calculated by using the Barrett Universal II formula preinstalled on the IOL-Master 700 (Software version 1.8, Carl Zeiss Meditech, Jena Germany). Company-labeled A-constant was 118.7 and 119.8 for I-Stream $\mathrm{H}$ and Lucia 221P, respectively.

Eyes of patients included in the study were randomly selected to be implanted with I-Stream H IOL (Group 1) or CT Lucia 211P one (Group 2). Surgical procedures were performed by one experienced high-volume surgeon (V.S.) using the same phacoemulsification device (Stellaris, Bausch\&Lomb, Rochester, NY, USA) and the phacochop technique. IOL insertion was done using a standard injector through a clear corneal superior incision $(2.5 \mathrm{~mm})$.

Statistical analysis was run using SPSS software version 19.0 (SPSS Inc., Chicago, Illinois, USA). Continuous variables were examined for normal distribution using the Kolmogorov-Smirnov test. Analysis of changes in parametric variables before and after surgery in the same groups was 
performed using Student $t$ test. Comparison of parametric variables of both groups was performed with nonparametric Mann-Whitney test. One-way ANOVA with Bonferroni posthoc test and Cochran's Q test were used to compare the two groups. A $p$ value $\leq 0.05$ was considered statistically significant.

\section{Results}

Overall, 94 patients (94 eyes) were included in the study: of these, 47 patients (22 M and $25 \mathrm{~F}$; mean age $74.94 \pm$ 7.68 years [range from 50 to 88 years]) were randomized to Group 1, while the remaining 47 (24 M and $23 \mathrm{~F}$; mean age $72.89 \pm 8.86$ years [range from 50 to 95 years]) were randomized to Group 2. Demographic and clinical data of both groups are summarized in Table 1.

After surgery, a significant increase of BCVA (Group 1: $0.43 \pm 0.72 \operatorname{LogMAR}$ at V0 vs $0.10 \pm 0.62$ at V3; Group 2: $0.39 \pm 0.64$ at V0 vs $0.15 \pm 0.62$ at V3), CS (Group 1: 1.08 \pm 0.23 at $\mathrm{V} 0$ vs $1.56 \pm 0.33$ at V3; Group 2: $1.12 \pm 0.35$ at $\mathrm{V} 0$ vs $1.53 \pm 0.41$ at V3) and VF-14 (Group 1: 83.31 \pm 1.02 at V0 vs $94.51 \pm 1.97$ at V3; Group 2: $81.54 \pm 2.78$ at V0 vs 93.29 \pm 2.08 at V3) and a significant decrease of SE (Group 1: $-0.49 \pm 2.22 \mathrm{D}$ at V0 vs $-0.31 \pm 0.71$ at V3; Group 2: -0.84 \pm 1.06 at $\mathrm{V} 0$ vs $-0.44 \pm 0.54$ at $\mathrm{V} 3$ ) were detected in both groups at each time point compared to baseline (always $\mathrm{p}<0.01)$. No significant differences in the post-operative increase of BCVA $(p=0.12), C S(p=0.21)$ and VF-14 $(\mathrm{p}=0.31)$ and decrease of SE $(\mathrm{p}=0.08)$ were detected comparing patients from Group 1 and Group 2 at V3 (Table 2). Mean and median prediction error values were, respectively, $0.3 \pm 0.6 \mathrm{D}$ and -0.4 for Group 1 and $0.2 \pm 0.5$ and -0.3 for Group 2 ( $\mathrm{p}>0.05)$. Similarly, absolute prediction error was $0.6 \pm 0.5$ and 0.5 for Group 1 and $0.7 \pm 0.5$ and 0.6 for Group $2(p>0.05)$. Eyes with an actual refraction within $0.25,0.50$ and $1.00 \mathrm{D}$ were $53.1 \%, 85.1 \%$ and $100 \%$, respectively, in Group 1; in Group 2 percentage was 55.3\%, 87.2\% and $100 \%$, respectively. No significant difference was recorded between the two groups $(p>0.05)$. During the entire followup period, none of the following complications (intraocular pressure spikes, IOL tilting or dislocation, posterior capsule opacification, long-lasting corneal edema, inflammatory or infective events) have been recorded in both groups.

\section{Discussion}

Visual impairment due to cataract still remains the leading cause of blindness in middle- and low-income countries, accounting for half cases of blindness. ${ }^{10-12}$ On the contrary, in developed countries where cataract surgery is the most performed surgical procedure, this type of visual impairment is responsible for only $5 \%$ of blindness cases. $^{13,14}$

The choice of the type of IOL implanted during cataract surgery depends upon patient's characteristics and expectations, surgeon preferences and settings (private Clinic vs Public Hospital). Overall, monofocal IOLs still represent the most implanted ones due to economic issues, good tolerability and poor/null contraindications. ${ }^{4}$

The present study aimed at comparing the visual performance of two newly-developed monofocal IOLs (I Stream H and CT Lucia 211P) implanted in patients with senile cataract. Visual performance was evaluated in the study through the testing of visual acuity, post-operative actual refraction, prediction error, CS and VF-14, a questionnaire specific for functional impairment secondary to cataract. Overall, all parameters improved significantly 1 month after surgery and this trend was maintained approximately unchanged over the entire study duration. Almost the totality of patients achieved a refractive

Table I Clinical Characteristics of Patients at Baseline and Surgical Parameters

\begin{tabular}{|c|c|c|c|c|c|}
\hline & \multicolumn{2}{|l|}{ Group I } & \multicolumn{2}{|l|}{ Group 2} & \multirow[t]{2}{*}{$\mathbf{p}$} \\
\hline & Mean \pm SD & Range & Mean \pm SD & Range & \\
\hline Age (years) & $74.94 \pm 7.68$ & 50 to 88 & $72.89 \pm 8.86$ & 50 to 95 & 0.37 \\
\hline BCVA (logMAR) & $0.43 \pm 0.72$ & 2.1 to 0.22 & $0.39 \pm 0.64$ & 2.1 to 0.19 & 0.22 \\
\hline SE (D) & $-0.49 \pm 2.22$ & -7 to +7.15 & $-0.84 \pm 1.06$ & -3 to +1.75 & $<0.001$ \\
\hline Mean keratometry (D) & $43.68 \pm 1.7$ & 39.51 to 48.25 & $43.91 \pm 1.6$ & 41.3 to 47.65 & 0.31 \\
\hline Axial length (mm) & $23.53 \pm 1.04$ & 20.85 to 26.01 & $23.58 \pm 0.77$ & $22.4 I$ to 25.07 & 0.09 \\
\hline $\mathrm{ACD}(\mathrm{mm})$ & $3.13 \pm 0.38$ & 2.57 to 4.01 & $3.28 \pm 0.32$ & 2.8 to 4.03 & 0.21 \\
\hline $\operatorname{ECD}\left(\right.$ cell $\left./ \mathrm{mm}^{2}\right)$ & $2345.53 \pm 167.83$ & 1894 to 2630 & $2262.57 \pm 171.96$ & 1980 to 2530 & 0.14 \\
\hline IOL power (D) & $21.14 \pm 2.74$ & 15 to 30 & $22.03 \pm 2.52$ & I 6.5 to 27.5 & 0.17 \\
\hline
\end{tabular}

Abbreviations: SD, standard deviation; BCVA, best correct visual acuity; SE, spherical equivalent; ACD, anterior chamber depth; ECD, endothelial cell density. 


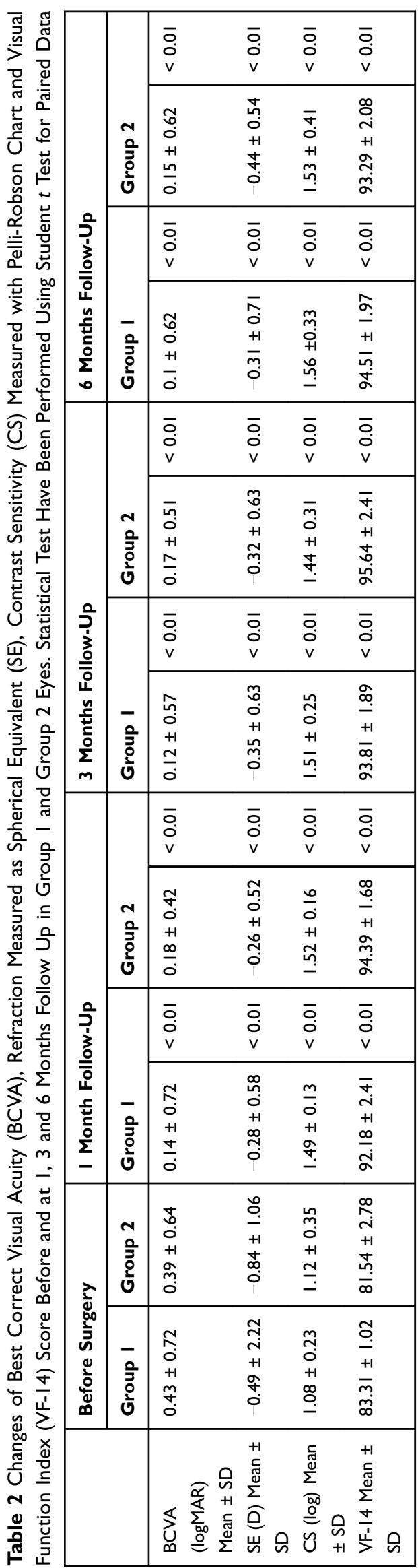

outcome with half diopter, regardless of the type of IOL implanted. Furthermore, no significant differences in the evaluated parameters were recorded between patients who were implanted with the two different IOLs. When comparing our results with those ones from other studies with other widely used monofocal IOLs, we found comparable values about CS and VF-14. ${ }^{15,16}$

This preliminary study validates the visual performance of either I-Stream H and CT Lucia 211P, and highlights their good profile of safety. This is a crucial aspect to consider when evaluating a new medical device introduced into the market.

The present study is preliminary and suffers from some limitations, including the small number of patients and the relatively short period of follow-up. However, an implementation of present data with a larger sample size and a longer follow-up is currently ongoing at our Institution to try to provide further evidence in this field.

In conclusion, I-Stream H and CT Lucia 211P allowed a satisfied recovery of visual function after senile cataract surgery with a good profile of safety. In addition, both IOLs were shown to have similar outcomes of visual performance.

\section{Disclosure}

The authors report no funding and no conflicts of interest in this work.

\section{References}

1. Liu YC, Wilkins M, Kim T, Malyugin B, Mehta JS. Cataracts. Lancet. 2017;390(10094):600-612. doi:10.1016/S0140-6736(17)30544-5

2. Olson RJ. Cataract surgery from 1918 to the present and future-just imagine! Am J Ophthalmol. 2018;185:10-13. doi:10.1016/j.ajo.2017. 08.020

3. Wang SY, Stem MS, Oren G, Shtein R, Lichter PR. Patient-centered and visual quality outcomes of premium cataract surgery: a systematic review. Eur J Ophthalmol. 2017;27(4):387-401. doi:10.5301/ejo.500 0978

4. de Silva SR, Evans JR, Kirthi V, Ziaei M, Leyland M. Multifocal versus monofocal intraocular lenses after cataract extraction. Cochrane Database Syst Rev. 2016;12:CD003169. doi:10.1002/14651858.CD0 03169.pub4

5. Chylack LT Jr, Wolfe JK, Singer DM, et al. The lens opacities classification system III. The longitudinal study of cataract study group. Arch Ophthalmol. 1993;111(6):831-836. doi:10.1001/archopht. 1993.01090060119035

6. Elliott DB, Sanderson K, Conkey A. The reliability of the Pelli-Robson contrast sensitivity chart. Ophthalmic Physiol Opt. 1990;10(1):21-24. doi:10.1111/opo.1990.10.issue-1

7. Pelli DG, Robson JG, Wilkins AJ. The design of a new chart for measuring contrast sensitivity. Clin Vis Sci. 1988;2:187-199.

8. Alonso J, Espallargues M, Andersen TF, et al. International applicability of the VF-14. An index of visual function in patients with cataracts. Ophthalmology. 1997;104(5):799-807. doi:10.1016/S01616420(97)30230-9 
9. Steinberg EP, Tielsch JM, Schein OD, et al. The VF-14, An index of functional impairment in patients with cataract. Arch Ophthalmol. 1994;112:630-638. doi:10.1001/archopht.1994.01090170074026

10. Song P, Wang H, Theodoratou E, Chan KY, Rudan I. The national and subnational prevalence of cataract and cataract blindness in China: a systematic review and meta-analysis. $J$ Glob Health. 2018;8(1):010804. doi:10.7189/jogh.08-010804

11. Batlle JF, Lansingh VC, Silva JC, Eckert KA, Resnikoff S. The cataract situation in Latin America: barriers to cataract surgery. $\mathrm{Am}$ J Ophthalmol. 2014;158:242-250. doi:10.1016/j.ajo.2014.04.019

12. Khanna R, Pujari S, Sangwan V. Cataract surgery in developing countries. Curr Opin Ophthalmol. 2011;22:10-14. doi:10.1097/ ICU.0b013e3283414f50
13. Lee CM, Afshari NA. The global state of cataract blindness. Curr Opin Ophthalmol. 2017;28(1):98-103. doi:10.1097/ICU.0000000000000340

14. Mundy KM, Nichols E, Lindsey J. Socioeconomic disparities in cataract prevalence, characteristics, and management. Semin Ophthalmol. 2016;31(4):358-363. doi:10.3109/08820538.2016.1154178

15. Lasta M, Mihaltz K, Kovacs I, et al. Effect of spherical aberration on the optical quality after implantation of two different aspherical intraocular lenses. J Ophthalmol. 2017:8039719. doi:10.1155/2017/ 8039719

16. Tarfah M, Samah M, Ahmed A. Corneal spherical aberration and its impact on choosing an intraocular lens for cataract surgery. Saudi J Ophthalmol. 2014;28:274-280. doi:10.1016/j.sjopt.2014.06.005
Clinical Ophthalmology

\section{Publish your work in this journal}

Clinical Ophthalmology is an international, peer-reviewed journal covering all subspecialties within ophthalmology. Key topics include: Optometry; Visual science; Pharmacology and drug therapy in eye diseases; Basic Sciences; Primary and Secondary eye care; Patient Safety and Quality of Care Improvements. This journal is indexed on PubMed

Submit your manuscript here: https://www.dovepress.com/clinical-ophthalmology-journal
Dovepress

Central and CAS, and is the official journal of The Society of Clinical Ophthalmology (SCO). The manuscript management system is completely online and includes a very quick and fair peer-review system, which is all easy to use. Visit http://www.dovepress.com/ testimonials.php to read real quotes from published authors. 